УДК 334.716:658.152

\author{
Янковий О.Г. \\ доктор економічних наук, професор \\ завідувач кафедри економіки підприємства \\ Одеський національний економічний університет \\ вул. Преображенська, 8, м. Одеса, Україна, 65082 \\ E-mail: yankovoy_a@ukr.net \\ Мельник Н.B. \\ кандидат економічних наук, викладач \\ кафедра менеджменту \\ Одеська філія Європейського університету \\ вул. Василя Стуса, 2-д, м. Одеса, Україна, 65033 \\ E-mail: vlad1984_8@te.net.ua \\ Янковий В.О. \\ кандидат економічних наук, старший викладач \\ кафедра економіки та управління національним господарством \\ Одеський національний економічний університет \\ вул. Преображенська, 8, м. Одеса, Україна, 65082 \\ E-mail: vladimir ya@ukr.net
}

\title{
ДО ПРОБЛЕМИ ВИЗНАЧЕННЯ ПРІОРИТЕТНОСТІ ІНВЕСТИЦІЙНИХ ПРОЕКТІВ ПРОМИСЛОВОГО ПІДПРИЄМСТВА
}

Розглядаються питання ранжирування інвестиційних проектів промислового підприємства на прикладі ПрАТ «Одесавинпром», яке відноситься до виноробної галузі України. За допомогою методів багатовимірного статистичного аналізу, зокрема, методу таксономії, визначаються ранги множини запланованих заходів на основі кількісних критеріїв економічної ефективності інвестиційних проектів: чистої приведеної вартості, резерву безпечності проекту, дисконтованого терміну окупності.

Ключові слова: пріоритетність, кількісні критерії, ефективність інвестиційних проектів, ранги.

Постановка проблеми та їі зв'язок 3 важливими науковими та практичними завданнями. Постійний дефіцит джерел фінансування, особливо в умовах перманентної фінансово-економічної кризи, що спостерігається в останні роки в промисловості України, в тому числі й у харчовій галузі, вимагає від менеджерів підприємств здійснення науково обгрунтованого ранжирування потенційно можливих проектів на базі значень важливіших критеріїв їх оцінки. В роботах [1-3] нами проаналізовано властивості й взаємозв'язки важливіших кількісних критеріїв оцінки інвестиційних проектів - чистої приведеної вартості $N P V$, модифікованої внутрішньої норми прибутку $M I R R$, резерву безпечності $M S$, дисконтованого терміну окупності проекту DPP. Проблема їх одночасного врахування автоматично приводить задачу визначення пріоритетності інвестиційних проектів до багатовимірного вигляду.

Аналіз останніх публікацій $з$ проблеми показав, що більшість сучасних науковців в області реального (виробничого) та фінансового вкладення коштів розглядають питання пріоритетності множини проектів 3 позицій класичної теорії інвестування, яка виходить із мети включення їх до майбутнього портфелю інвестицій і подальшого складання фінансового бюджету підприємства. Пріоритетність проектів, зазвичай, визначається на основі величини інвестиційних коштів, які менеджери можуть дозволити витратити в майбутньому періоді (див. роботи [4-7]). На наш погляд, такий підхід страждає однобічністю и необгрунтованістю, оскільки він заснований переважно на базі лише одного $з$ перелічених вище критеріїв інвестиційних проектів.

Формулювання цілей дослідження. Мета даної статті - викласти методичні підходи до визначення пріоритетності множини інвестиційних проектів промислового підприємства 3 одночасним урахуванням декількох кількісних критеріїв їх економічної доцільності за допомогою методів багатовимірного статистичного аналізу, зокрема, методів таксономії.

Виклад основних результатів та їх обгрунтування. Розглянемо поставлену теоретичну і практичну проблему на прикладі одного з лідерів виноробної галузі України - ПрАТ «Одесавинпром» [8].

Визначимо пріоритетність запланованих на 2015 р. реальних інвестицій техніко-технологічного та організаційно-економічного характеру на заводах первинного i вторинного виноробства товариства. Для досягнення поставленої мети застосуємо багатовимірні статистичні методи, а саме, таксономічний аналіз, який включає вісім головних етапів, котрі будуть детально розглянуті за даними поставленої задачі.

1. Формування матриці вихідних даних $\boldsymbol{X}$. По кожному з потенційно корисних виробничих проектів були розраховані кількісні значення трьох основних критеріїв оцінки обговорюваних реальних інвестицій $(N P V, M S, D P P)$ і відібрані лише 8 прийнятних з економічної точки зору заходів (табл. 1 ). 
Таблиця 1

Значення основних критеріїв оцінки реальних інвестицій на ПрАТ «Одесавинпром»

\begin{tabular}{|l|c|c|c|}
\hline \multicolumn{1}{|c|}{ Виробничих захід } & $\begin{array}{c}N P V, \\
\text { тис. грн. }\end{array}$ & $\begin{array}{c}M S \text { (абсо- } \\
\text { лют., п. п.) }\end{array}$ & $\begin{array}{c}\text { DPP, } \\
\text { років }\end{array}$ \\
\hline $\begin{array}{l}\text { 1. Оптимізація сировинних зон для заводів первинної обро- } \\
\text { бки }\end{array}$ & 24,53 & 1,1 & 6,7 \\
\hline $\begin{array}{l}\text { 2. Заміна застарілого насосного обладнання на поршневі } \\
\text { насоси з нержавіючої сталі AISI 304 }\end{array}$ & 5,68 & 4,9 & 2,8 \\
\hline $\begin{array}{l}\text { 3. Впровадження декантерних центрифуг Fоодес 300 виро- } \\
\text { бництва, які призначені для розділення сусла на виноград- } \\
\text { ний сік і жмих. }\end{array}$ & 32,21 & 0,5 & 7,1 \\
\hline $\begin{array}{l}\text { 4. Облаштування автоматичної системи стабілізації проти } \\
\text { випадання винного каменя }\end{array}$ & 13,95 & 2,7 & 3,5 \\
\hline $\begin{array}{l}\text { 5. Частковий перехід до використання високоякісної агло- } \\
\text { мерованої пробки DІАМ, властивості якої наближені до на- } \\
\text { туральної пробки. }\end{array}$ & 19,11 & 0,9 & 4,2 \\
\hline $\begin{array}{l}\text { 6. Подальше комбінування виробництва шляхом опрацю- } \\
\text { вання технологій випуску кормового та харчового білка, } \\
\text { харчових добавок і біологічно активних речовин з відходів } \\
\text { виноробства }\end{array}$ & 4,56 & 3,8 & 2,2 \\
\hline $\begin{array}{l}\text { 7. Створення інвестиційно-інноваційної науково-технічної } \\
\text { групи, у функції якої буде входити моніторинг найкращих } \\
\text { вітчизняних та іноземних «ноу-хау» в області виноробства }\end{array}$ & 8,72 & 3,1 & 2,6 \\
\hline $\begin{array}{l}\text { 8. Удосконалення інформаційних зв'язків між підрозділами } \\
\text { товариства, впровадження електронного документообігу і } \\
\text { системи бюджетування витрат }\end{array}$ & 30,25 & 0,3 & 6,5 \\
\hline
\end{tabular}

Отже, матриця вихідних даних $\boldsymbol{X}$ має наступний вигляд:

$$
\boldsymbol{X}=\left(\begin{array}{ccc} 
& & \\
24,53 & 1,1 & 6,7 \\
5,68 & 4,9 & 2,8 \\
32,21 & 0,5 & 7,1 \\
13,95 & 2,7 & 3,5 \\
19,11 & 0,9 & 4,2 \\
4,56 & 3,8 & 2,2 \\
8,72 & 3,1 & 2,6 \\
30,25 & 0,3 & 6,5 \\
& &
\end{array}\right)
$$

2. Розділення обраних критеріїв на стимулятори і дестимулятори здійснюється на основі визначення напряму зв'язку кожного з обраних показників 3 пріоритетністю проекту, котра розглядається як латентна ознака, що не підлягає безпосередньому вимірюванню. Очевидно, що в даній задачі критерії $N P V$, $M S$ є стимуляторами, високі значення яких є бажаними для всіх інвестиційних проектів, а показник $D P P$ - дестимулятором (термін окупності повинен бути малим).
3. Стандартизація значень критеріїв за формулою

$$
Z_{i}=\frac{X_{i j}-\overline{X_{j}}}{\sigma_{j}}
$$

де $X_{\mathrm{ij}}$ - спостережуване значення $j$-го критерію для $i$ го інвестиційного проекту $(j=1,2,3 ; i=1,2, \ldots, 8)$; 
$\overline{X_{\mathrm{j}}}, \sigma_{\mathrm{j}}-$ середнє значення і стандартне відхилення $j$-го критерію.

Перехід до матриці $\boldsymbol{Z}$ відбувається автоматично в системі програм STATISTICA в модулі «Клас терний аналіз» [9; 10]. В результаті розрахунків на персональному комп'ютері отримано наступну матрицю стандартизованих значень трьох критеріїв для досліджуваних інвестиційних проектів:

$$
Z=\left(\begin{array}{rrr}
0,658 & -0,624 & 1,116 \\
-1,076 & 1,608 & -0,818 \\
1,364 & -0,976 & 1,314 \\
-0,316 & 0,315 & -0,471 \\
0,160 & -0,741 & -0,124 \\
-1,179 & 0,962 & -1,116 \\
-0,796 & 0,551 & -0,917 \\
1,184 & -1,094 & 1,017
\end{array}\right)
$$

Усі значення матриці $\boldsymbol{Z}$ вільні від одиниць виміру і знаходяться в межах от -2 до 2. При цьому сума по стовпцю дорівнює нулю, а дисперсія - одиниці.

4. Визначення і врахування статистичних ваг $f_{\mathrm{j}}$ відібраних критеріїв відбувається в кожній конкретній задачі на базі тих цільових установок інвестиційної політики, яку прийняло керівництва підприємства. В даному випадку менеджери ПрАТ «Одесавинпром» налаштовані на максимальне підвищення капіталу товариства.

Оскільки в дослідженні використовуються лише три критерії оцінки інвестицій і перевага відда- ється показнику $N P V$, що відображає потенційний прибуток об'єднання, то статистичні ваги виглядають так: $f_{1}=0,5 ; f_{2}=0,3 ; f_{3}=0,2$. Це означає, що важливість чистої приведеної вартості проектів розцінюється майже в 1,7 рази вище їх безпечності, і в 2,5 рази вище їх ліквідності. При цьому виконується стандартна вимога $f_{1}+f_{2}+f_{3}=1$.

Звідси, матриця стандартизованих даних $\boldsymbol{Z} 3$ урахуванням статистичних ваг розраховується шляхом множення кожного стовпця матриці (3) на відповідне значення $f_{\mathrm{j}}$ i має кінцевий вигляд, представлений в табл. 2.

Таблиця 2

Кінцевий вигляд матриці стандартизов
\begin{tabular}{|r|r|r|}
\hline VAR1 & \multicolumn{1}{|c|}{ VAR2 } & \multicolumn{1}{c|}{ VAR3 } \\
\hline 0,3289 & $-0,1872$ & 0,2232 \\
$-0,5378$ & 0,4823 & $-0,1637$ \\
0,6821 & $-0,2929$ & 0,2628 \\
$-0,1575$ & 0,0947 & $-0,0942$ \\
0,0797 & $-0,2224$ & $-0,0248$ \\
$-0,5893$ & 0,2885 & $-0,2232$ \\
$-0,398$ & 0,1652 & $-0,1835$ \\
0,592 & $-0,3281$ & 0,2033 \\
\hline
\end{tabular}

5. Завдання проекту-еталона здійснюється на основі значень критеріїв даної сукупності інвестиційних проектів 3 табл. 2, а саме: для критеріївстимуляторів за максимумом, а для критеріївдестимуляторів за мінімумом. В результаті проектеталон має координати $z_{0 j}(0,6821 ; 0,4823 ;-0,2232)$. Це умовна точка в трьохвимірному просторі критеріїв, оскільки найбільші значення $N P V$ i $M S$ належать третьому і другому, а найменший $D P P$ - шостому проекту.
6. У якості функції відстані між проектами і еталоном скористуємося найбільш популярною в економічних дослідженнях евклідовою метрикою:

$$
d\left(z_{i}, z_{0}\right)=\sum_{j=1}^{3} \sqrt{\left(z_{i j}-z_{0 j}\right)^{2}}
$$




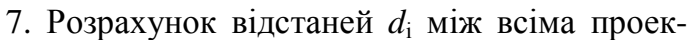
тами і еталоном відбувається автоматично в системі програм STATISTICA у модулі «Кластерний аналіз»
[9; 10]. В результаті розрахунків на персональному комп’ютері отримано наступну матрицю (табл. 3).

Таблиця 3

Евклідові відстані від кожного інвестиційного проекту до еталона

\begin{tabular}{|c|c|c|c|c|c|c|c|c|c|}
\hline Проект & 1 & 2 & 3 & 4 & 5 & 6 & 7 & 8 & Еталон \\
\hline Еталон & 0,8787 & 1,2214 & 0,9149 & 0,9337 & 0,9481 & 1,2861 & 1,1264 & 0,9202 & 0 \\
\hline
\end{tabular}

Візуальний аналіз даних табл. 3 показує, що найближче всіх інвестиційних проектів до еталону знаходиться захід № $1\left(d_{1}=0,8787\right)$, а найдальше інвестиція № $6\left(d_{6}=1,2861\right)$. Самі значення відстаней $d_{\mathrm{i}}$ інвестиційних проектів до еталона можна розглядати як величини синтетичних резервів росту пріоритетності кожного заходу.

8. Розрахунок мір схожості $\mu_{\mathrm{i}}$ аналізованих проектів з еталоном та їх ранжирування проводиться для більш наочного виділення груп заходів-лідерів і аутсайдерів. Воно зазвичай здійснюється в редакторі Excel за формулою

$$
\mu_{\mathrm{i}}=1 /\left(1+d_{\mathrm{i}}\right)
$$

на базі розрахованих відстаней $d_{\mathrm{i}}$ (табл. 3). Результати визначення мір схожості і відповідних їм рангів кожного інвестиційного проекту підприємства представлені в табл. 4.

Таблиця 4

Результати ранжирування інвестиційних проектів ПрАТ «Одесавинпром» за методом таксономії

\begin{tabular}{|l|c|c|c|c|c|c|c|c|c|}
\hline Проект & 1 & 2 & 3 & 4 & 5 & 6 & 7 & 8 & Еталон \\
\hline $\begin{array}{l}\text { Схожість } \\
\text { з еталоном }\end{array}$ & 0,5322 & 0,4501 & 0,5222 & 0,5171 & 0,5133 & 0,4374 & 0,4702 & 0,5207 & 1 \\
\hline Ранг & 1 & 7 & 2 & 4 & 5 & 8 & 6 & 3 & - \\
\hline
\end{tabular}

Аналіз даних табл. 4 показує, що серед досліджуваних інвестиційних проектів можна виділити, принаймні, три групи або кластери. В перший кластер входять найбільш пріоритетні заходи - № $1\left(\mu_{1}=\right.$ 0,5322), № $3\left(\mu_{3}=0,5222\right)$ i № $8\left(\mu_{8}=0,5207\right)$, що посіли 1-3 місця в табелі про ранги. Це інвестиції-лідери за висунутими вимогами щодо іх прибутковості, ризикованості й ліквідності. У другий кластер потрапили проекти-середняки - № $4\left(\mu_{4}=0,5171\right)$, № $5\left(\mu_{5}=\right.$ $0,5133)$, які отримали ранги 4,5 відповідно. I в третій кластер увійшли інвестиції-аутсайдери - № $7\left(\mu_{7}=\right.$ 0,4702), № $2\left(\mu_{2}=0,4501\right)$, № $6\left(\mu_{6}=0,4374\right)$. Вони зайняли 6-8 місця у побудованій класифікації.

Висновки та перспективи подальших досліджень. Беззаперечним інвестиційним проектом- лідером виявилася оптимізація сировинних зон для заводів первинної обробки з метою зниження собівартості виноградної сировини, збільшення завантаженості виробничих потужностей і скорочення транспортних витрат. На другому місці щодо пріоритетності знаходиться захід 3 впровадження декантерних центрифуг Foodec 300, які призначені для розділення сусла на виноградний сік і тверді частинки. Отримані результати комплексно і одночасно враховують усі важливіші вимоги, яким повинні відповідати сучасні проекти реальних інвестицій. Вони можуть служити надійним орієнтиром у процесі подальшого вдосконалення виробництва якісної винно-коньячної продукції ПрАТ «Одесавинпром».

\section{Література}

1. Янковий О. Г. Критичний аналіз внутрішньої норми прибутку як показника оцінки інвестиційних проектів / О. Г. Янковий, Н. В. Мельник // Вісник соціально-економічних досліджень. - ОНЕУ, 2012. - № 45. C. $196-205$.

2. Янковий О. Г. Модифікована внутрішня норма прибутку інвестиційного проекту / О. Г. Янковий, Н. В. Мельник // Прикладной менеджмент и инвестиции. - 2012. - № 4. - С. 502-508.

3. Янковий О. Г. Оцінка інвестиційних проектів на підприємствах харчової промисловості України / О. Г. Янковий, Н. В. Мельник, В. О. Янковий // Економіка харчової промисловості. - 2013. - № 2(18). - С. 49-53.

4. Гукалюк А. Ф. Процедура порівняння ефективності портфеля цінних паперів як елемент визначення інвестиційної привабливості / А. Ф. Гукалюк // Актуальні проблеми економіки. - 2005. - № 4 (22). - С. 4 -9.

5. Інвестиційно-фінансовий портфель (Книга інвестиційного менеджера. Книга фінансового менеджера. Книга фінансового посередника). / [відп. ред. Ю. Б. Рубін, В. І. Солдаткін]. - М. : "СОМІНТЕК", 2002. - 282 c.

6. Ковалев В. В. Методы оценки инвестиционных проектов / Ковалев В. В. - М. : Финансы и статистика, 2003. - 144 с.

7. Стасюк В. П. Моделирование процессов инвестиционной деятельности предприятия. Модели адаптивного управления предприятием: [монография] / В. П. Стасюк. - Донецк : Юго-Восток, 2003. - С. 77-104. 
8. Одесавинпром, ПрАТ [Електронний ресурс]. - Режим доступу : http://fbulvar.business-guide.com.ua/

9. Боровиков В. П. STATISTICA - Статистический анализ и обработка данных в среде Windows / B. П. Боровиков, И. П. Боровиков. - М. : ИИД «Филинъ», 1998. - 608 с.

10. Боровиков В. П. Популярное введение в программу STATISTICA / Боровиков В. П. - М. : КомпьютерПресс, 1998. - 267 с.

Янковой А.Г.

доктор экономических наук, профессор заведующий кафедрой экономики предприятия Одесский национальный экономический университет ул. Преображенская, 8, г. Одесса, Украина, 65082 E-mail: yankovoy a@ukr.net

Мельник Н.В.

кандидат экономических наук, преподаватель кафедра менеджмента

Одесский филиал Европейского университета

ул. Василия Стуса, 2-д, г. Одесса, Украина,65033

E-mail: vlad1984_8@te.net.ua

Янковой В.A.

кандидат экономических наук, старший преподаватель кафедра экономики и управления национальным хозяйством

Одесский национальный экономический университет

ул. Преображенская, 8, г. Одесса, Украина, 65082

E-mail: vladimir_ya@ukr.net

\section{К ПРОБЛЕМЕ ОПРЕДЕЛЕНИЯ ПРИОРИТЕТНОСТИ ИНВЕСТИЦИОННЫХ ПРОЕКТОВ ПРОМЫШЛЕННОГО ПРЕДПРИЯТИЯ}

Постоянный дефицит источников финансирования, особенно в условиях перманентного финансовоэкономического кризиса, который наблюдается в последние годы в промышленности Украины, в том числе и в пищевой отрасли, требует от менеджеров предприятия осуществления научно обоснованного ранжирования возможных проектов на базе значений важнейших критериев их оценки. В данной статье рассматриваются вопросы ранжирования инвестиционных проектов промышленного предприятия с помощью методов многомерного статистического анализа, в частности, метода таксономии. Последний включает восемь главных этапов, важнейшими из которых являются формирование матрицы исходных данных, разделение факторов на стимуляторы и дестимуляторы и их стандартизация, определение и учет статистических весов отобранных фракторов, задание точки-эталона, выбор функции расстояния между объектами и эталоном, расчет расстояний между всеми объектами и эталоном, расчет мер сходства рассматриваемых объектов с эталоном и их ранжирование. Поставленная теоретическая и практическая проблема решена на примере одного из лидеров винодельческой отрасли Украины - ЗАО «Одессавинпром», выпускающего свою продукцию под эгидой известной торговой марки «Французский бульвар». Для данного предприятия определены ранги множества запланированных производственных мероприятий на основе количественных критериев экономической эффективности инвестиционных проектов - чистой приведенной стоимости, резерва безопасности проекта, дисконтированного срока окупаемости. Проведенное исследование показало, что среди исследуемых инвестиционных проектов можно выделить, по крайней мере, три кластера. Безоговорочным инвестиционным проектом-лидером оказалась оптимизация сырьевых зон для заводов первичной обработки с целью снижения себестоимости виноградного сырья, увеличения загруженности производственных мощностей и сокращения транспортных расходов. На втором месте по приоритетности находится мероприятие по внедрению декантерных центрифуг Foodec 300 производства шведской фирмы Альфа Лаваль, которые предназначены для разделения сусла на виноградный сок и твердые частицы. Полученные результаты комплексно и одновременно учитывают все важные требования, которым должны соответствовать современные проекты реальных инвестиций. Они могут служить надежным ориентиром в процессе дальнейшего совершенствования производства качественной винной и коньячной продукции ЗАО «Одессавинпром».

Ключевые слова: приоритетность, количественные критерии, эфффективность инвестиционных проектов, ранги. 


\author{
lankovyi O.G, \\ Doctor of Economic Sciences, Professor \\ Head of the Department of Economy of Enterprise \\ Odessa National Economic University \\ Preobragenska Str., 8, Odessa, Ukraine, 65082 \\ E-mail: yankovoy a@ukr.net \\ Melnik N.V. \\ Ph.D. in Economics, lecturer \\ Department of management \\ The Odessa branch of the European University \\ Vasyl Stus Str., 2-d, Ukraine, Odessa, 65033 \\ E-mail: vlad1984_8@te.net.ua \\ lankovyi V.O. \\ Ph.D. in Economics, Senior lecturer \\ Department of Economics and Management of National Economy \\ Odessa National Economic University \\ Preobragenska Str., 8, Odessa, Ukraine, 65082 \\ E-mail: vladimir_ya@ukr.net
}

\title{
TO THE PROBLEM OF DETERMINING THE PRIORITY OF INVESTMENT PROJECTS OF INDUSTRIAL ENTERPRISE
}

\begin{abstract}
Permanent deficit of financial resources, especially in conditions of permanent financial crisis observed in recent years in the industry of Ukraine, including in the food industry, makes managers of companies to implement scientificallybased ranking of the potential projects based on values important criteria for their evaluation.

The ranking of investment projects of industrial enterprises using multivariate statistical analysis methods, including the method of taxonomy was discussed in this article. The method of taxonomy includes eight main stages, the most important among them are to form the matrix of initial data, to separate factors for stimulants and non-stimulants and their standardization, to identify and take into account the statistical weights of selected factors, to select pointstandard, to choose the distance function between objects and point-standard, calculation of distances between all objects and a point-standard, calculation of similarity measures of analyzed objects with point-standard and their ranking.

The stated theoretical and practical problem was solved on example of one of the leaders in the wine industry of Ukraine - PJSC "Odesavinprom", which produces products under the well-known trade mark "French Boulevard". For this enterprise the ranks of set of planned production activities based on quantitative criteria of economic efficiency of investment projects - net present value, reserve safety project, discounted payback period was determined.

The research showed that among the reviewed investment projects at least three clusters can be allocated. The optimization of raw material areas for primary processing plants to reduce the cost of grapes, increase load capacity and reduce transport costs is doubtless investment project leader. The second priority is the implementation of decanting centrifuges Foodec 300 produced by the Swedish company Alfa Laval, which are designed to separate the mash on grape juice and solids. The results comprehensively and simultaneously take into account all the important requirements which must be met by modern projects of real investment. They can be a reliable guide in the process of further improving the production of quality wine and brandy production of PJSC "Odesavinprom."
\end{abstract}

Keywords: priority, quantitative criteria, the effectiveness of investment projects, ranks.

\section{References}

1. Yankovyi O. H. (2012). Krytychnyi analiz vnutrishnoi normy prybutku yak pokaznyka otsinky investytsiinykh proektiv. O. H. Yankovyi, N. V. Melnyk. Visnyk sotsialno-ekonomichnykh doslidzhen. ONEU, № 45, $196-205$.

2. Yankovyi O. H. (2012). Modyfikovana vnutrishnia norma prybutku investytsiinoho proektu. O. H. Yankovyi, N. V. Melnyk. Prykladnoi menedzhment y ynvestytsyy. № 4, 502-508.

3. Yankovyi O. H. (2013). Otsinka investytsiinykh proektiv na pidpryiemstvakh kharchovoi promyslovosti Ukrainy. O. H. Yankovyi, N. V. Melnyk, V. O. Yankovyi. Ekonomika kharchovoi promyslovosti. № 2(18), $49-53$.

4. Hukaliuk A. F. (2005). Protsedura porivniannia efektyvnosti portfelia tsinnykh paperiv yak element vyznachennia investytsiinoi pryvablyvosti. Aktualni problemy ekonomiky. № 4 (22), 4-9.

5. Investytsiino-finansovyi portfel (Knyha investytsiinoho menedzhera. Knyha finansovoho menedzhera. Knyha finansovoho poserednyka). [vidp. red. Yu. B. Rubin, V. I. Soldatkin] (2002). M. : "SOMINTEK", 282.

6. Kovalev V. V. (2003). Metody otsenky ynvestytsyonnykh proektov. M. : Fynansy y statystyka, 144.

7. Stasiuk V. P. (2003). Modelyrovanye protsessov ynvestytsyonnoi deiatelnosty predpryiatyia. Modely adaptyvnoho upravlenyia predpryiatyem: [monohrafyia]. Donetsk : Yuho-Vostok, 77-104.

8. Odesavynprom, PrAT. [Elektronnyi resurs]. Rezhym dostupu : http://fbulvar.business-guide.com.ua/.

9. Borovykov V. P. (1998). STATISTICA Statystycheskyi analyz y obrabotka dannykh v srede Windows / V. P. Borovykov, Y. P. Borovykov. M. : YYD «Fylynъ», 608.

10. Borovykov V. P. (1998). Populiarnoe vvedenye v prohrammu STATISTICA M. : KompiuterPress, 267. 